\title{
Patients' perception of safety in four hospitals in Tamaulipas, Mexico
}

\author{
Concepción Meléndez Méndez, Rosalinda Garza Hernández, Juana Fernanda González Salinas, Socorro Rangel Torres, \\ Gloria Acevedo Porras, Hortensia Castañeda-Hidalgo* \\ Facultad de Enfermería de Tampico, Universidad Autónoma de Tamaulipas, Mexico
}

Received: August 2, 2017

Accepted: October 19, 2017

Online Published: October 25, 2017

DOI: $10.5430 /$ jha.v6n6p15

URL: https://doi.org/10.5430/jha.v6n6p15

\begin{abstract}
Objective: To determine the perceived patient safety related to health care during hospitalization. To identify the number of patients who report having suffered a clinical error and describe the patients' experience with the clinical error.

Methods: A cross-sectional descriptive study performed of patients who were hospitalized between August-November 2013 in four second-level hospitals.

Results: A total of 631 patients were surveyed. Regarding the errors suffered during the hospitalization, $7.9 \%$ of the patients reported having suffered a complication, $7.9 \%$ reported having an infection, 5.2\% had an allergic reaction to medication and 5.1\% had to undergo a second surgery. Regarding the patients' responses about the experience with the error, only $4.8 \%$ of the patients reported having had experiencing clinical error in their management, $1.9 \%$ mentioned that they fully agreed that the error was solved quickly, $2.5 \%$ that the error was solved satisfactorily and $3.3 \%$ patients disagreed as they were not informed if steps would be taken to prevent the error from recurring.

Conclusions: To address safety culture in the hope of improving patient safety will continue to motivate nurse researchers and managers thus more research about patient perception is needed.
\end{abstract}

Key Words: Safety, Patients' perception, Clinical error

\section{INTRODUCTION}

It is becoming increasingly recognized that patients can make valuable contributions to health safety. In the United Kingdom, the Department of Health is building a safer system for patients: A report was made that emphasized the need to create a clear role for patients to help, promote and achieve the safety objectives. As a result of this report, the National Agency for Patient Safety was established, which since its inception has promoted the need for patients' participation in safety. This was achieved through numerous leaflets and campaigns to encourage active patient participation in conjunction with specific guidelines for health personnel on how to communicate with patients or families following the error or injury. ${ }^{[1]}$ The appropriate and interactive information forms the basis for the perceived patient safety. The correct management of uncertainty in the patient-professional relationship improves safety, builds an environment of trust and generates satisfaction in the patient. It is therefore the responsibility of health professionals, among others, to join hands with the patient to achieve the highest quality and safety in the care given. It is necessary to have a change in culture that enhances learning from past mistakes aimed at providing patients with safe and quality services. ${ }^{[2]}$

Directly asking the patients has raised some doubts about the

\footnotetext{
* Correspondence: Hortensia Castañeda-Hidalgo; Email: hcastane@docentes.uat.edu.mx; Address: Facultad de Enfermería de Tampico, Universidad Autónoma de Tamaulipas, Blvd. Adolfo López Mateos s/n, Tampico, Tamaulipas, México.
}

Published by Sciedu Press 
reliability of the information obtained. However, new studies have shown that patients can be reliable reporters, especially when the adverse event (AE) has more serious consequences. Patient's involvement in safety has been emphasized as a necessity for the clinical practice, so it is necessary for the patient to be aware of the inherent risks in the practice. This point is important because recent data indicate that less than half of Spaniards expect clinical errors to occur, while most believe that they are unlikely. ${ }^{[3]}$ The probability of suffering an $\mathrm{AE}$ is not insignificant, studies on clinical safety perception either identify the frequency of $\mathrm{AE}$ or inquire whether patients feel safe. In Spain, 8.4\% of hospitalized patients and $10.1 \%$ in primary care suffer an AE. A total of $9 \%$ of Europeans, $5 \%$ of Australians and 3\% of Canadians believe that the likelihood of an error is high. For $31 \%$ of Spaniards there are many clinical errors and $12 \%$ considered that the risk of a surgical error to be high. ${ }^{[4,5]}$

Between $4 \%$ and $17 \%$ of patients admitted in a hospital will suffer an unforeseen and unexpected accident, resulting from health care and not from their underlying disease, which will have consequences on their health status and subsequent recovery. In some cases, these errors will result in death. In the United States it is estimated that between 44,000 and 98,000 people die each year for this reason. Health care is increasingly complex. It uses more sophisticated technologies, more contributions are made, the diversity of professionals and the variability of their practices are increasing. Therefore, receiving health care entails increasing potential risks, even when every day millions of people are treated successfully and safely on daily bases. The interest in studying and controlling the risks of health care is not new. In 1964, Schimmel reported that $20 \%$ of patients admitted in hospitals had some iatrogeny and, that one in five was severe. The World Health Organization (WHO) highlights the role of the patient in clinical safety. Some agencies, such as the Agency for Research and Quality (AHRQ) and the National Health Service (NHS), have carried out campaigns to encourage a more active role of the patient in the interests of safety related issues. In Spain, the Quality Agency of the Ministry of Health held a conference on the role of patients in clinical safety in December 2007, aimed at raising awareness among the different agencies about the importance of safety in the quality of health care. Although the idea of what a (healthy) population perceives of safety has been established, through the Eurobarometer 2006 to date, there is not much known about the perceived patient safety and their experiences with AEs. ${ }^{[6]}$

In Latin America, incidents related to patient safety affect up to a $10 \%$ admitted. A quarter of these patient safety incidents result in serious consequences, such as disability or death.
Consequently, the investigation of incidents of patient safety has aroused great interest. A number of studies have focused on this subject matter and concluded that programs should be established urgently to prevent incidents in patient safety, their frequency and impact. The publication by the Institute of Medicine of the United States of the report "To Err is Human" marked the beginning of an international political agenda in patient safety. Since then the patient safety agenda has reached remarkable achievements, often in close collaboration with patients who have suffered safety incidents. The participation of patients in incident prevention is spreading in the United States, Canada, Colombia and Mexico. ${ }^{[7]}$

Reducing medical errors or AEs has been a concern that is becoming a matter of international concern. In Mexico, as in most developing countries, no system for reports of AEs has been implemented in health care, so no data is available. In response to the situation in October 2004, WHO established the Patient Safety Alliance to improve patient safety in both developed and developing countries. ${ }^{[8]}$

Building links between patients and health professionals after the presentation of an event is critically important. Therefore the National Forum for Quality recently published in its 2010 report, Safe Practices for Better Health Care, and one of the recommendations is that the patient should receive timely, transparent and clear information regarding what is known of the AE. A patient is more likely to respond more favorably to a health care provider who provides complete information about iatrogenic injury, than to a professional who behaves defensively or untruthfully. Patients can express their perception about whether the AE was preventable and provide specific information on how to avoid it. ${ }^{[9]}$

In Mexico, the Health Sector has promoted a series of recommendations related to patient safety, including patient identification, clear communication, drug management (The 5 rights of medication administration: the right patient, the right drug, the right dose, the right route, the right time), safe surgery steps (correct patient, correct surgery and procedure, correct surgical site and correct timing), avoiding patient falls, use of protocols and guidelines, avoiding nosocomial infections, safety climate, human factors, having the patient be a part of decision-making, these recommendations are promoted with the purpose of promoting the quality of patient care. ${ }^{[10]}$

\section{METHODS}

Descriptive cross sectional study, ${ }^{[11]}$ was carried out from August $14^{t h}$ to November $30^{t h}, 2013$, in four secondary health care hospitals, located in Tampico and Cd Madero, Tamaulipas, Mexico. Non-probabilistic sampling method was used for the study. The total sample was 631 patients. 
The inclusion criteria used were: patients of both sexes over 18 years old, discharged, mentally fit and with a hospital stay longer than three days. The recruitment and selection of the patients that fulfilled the inclusion criteria was performed in the different hospitalization services of the institutions involved and with the corresponding permits from the health institutions. Patients were approached and those who consented to participate were recruited for the study. The instrument used for the data collection was a questionnaire that measures the patient's perception about safety in health care (PSHC), in hospital settings, adapted from Badia et al. ${ }^{[12]}$

The questionnaire consists of 24 questions divided into three sections. Section A contains 10 questions on perceived safety of patients during hospitalization. Each question consists of answer options on a 5-point Likert Scale (1: I do not agree to 5: I completely agree). In Section B, the patient must respond if he/she has experienced any clinical error during his/her hospitalization, through seven questions with dichotomous response options yes/no. The third part of the questionnaire (Section C) seeks responses on the patient's experience of clinical error using seven questions on a 5-point Likert continuum (1: I do not agree to 5: I completely agree). A last question asked comprises a general question about the perceived effect of attention received during hospitalization; using seven response options. The overall assessment of safety perceived by patients, was obtained from the standardized score of the questionnaire, taking into account only the questions from 1 to 10 . For data capture and processing, a database was designed in the statistical package SPSS version 17. The analysis was descriptive, with frequencies and percentages were used to measure the internal consistency of the instrument. Cronbach's Alpha coefficient was used for the full scale and the subscales. To measure the overall perceived safety, the mean of the total sum of the perception scale was calculated.

In accordance with the regulations of the general law on health in research in Mexico, ${ }^{[13]}$ the study was considered safe, since only a questionnaire was applied to the participants and no intervention was performed, which would damage their integrity. Ethical clearance for the study was obtained from the research and ethics committee of the Tampico School of Nursing of the Universidad Autónoma de Tamaulipas, as well as the relevant committees of other institutions used.

\section{RESULTS}

The results obtained are: the predominance of female patients was observed, with 336 female participants (53.2\%), the majority of participants had only completed elementary school $(242,38.4 \%)$, the mean age was 53 . The mean num- ber of days of hospitalization was 9.06, and 581 (92.1\%) of the patients did not report complications during their hospitalization and only $50(7.9 \%)$ had had complications (see Table 1).

Table 1. Sociodemographic characteristics

\begin{tabular}{lll}
\hline Variable & $\boldsymbol{f}$ & $\mathbf{\%}$ \\
\hline Sex & & \\
- Female & 336 & 53.2 \\
- Male & 295 & 46.8 \\
Level of schooling & & \\
- Elementary & 242 & 38.4 \\
- High school & 114 & 18.1 \\
- College & 129 & 20.4 \\
Technical & 24 & 3.8 \\
Graduate & 70 & 11.1 \\
No studies & 52 & 8.2 \\
\hline
\end{tabular}

Note. Source: Field survey, 2013; $n=631$

Regarding the perceived safety, the mean obtained from the perception scale of the questionnaire was $42.4 \pm 8.28$ with a minimum value of 15 and a maximum value of 50 , so the overall perceived safety of the interviewed patients was considered to be very good since more than $50 \%$ of the patients with "completely safe" responses were above the 50th percentile (see Table 2).

Table 2. Results of patients' perception of safety

\begin{tabular}{lllll}
\hline \multirow{2}{*}{$\begin{array}{l}\text { Perception } \\
\text { scale }\end{array}$} & \multirow{2}{*}{ Mean } & SD & \multicolumn{2}{c}{ Values } \\
\cline { 3 - 5 } & & Minimum & Maximum \\
\hline Items 1-10 & 42.4 & 8.28 & 15 & 50 \\
\hline Note. Source: PSHC; $n=631$ &
\end{tabular}

The errors that patients reported having suffered during hospitalization the results are presented in Table 3.

Table 3. Presented health problems reported by patients during hospitalization

\begin{tabular}{|c|c|c|c|c|}
\hline \multirow{2}{*}{ Health problems reported } & \multicolumn{2}{|c|}{ Yes } & \multicolumn{2}{|c|}{ No } \\
\hline & $f$ & $\%$ & $f$ & $\%$ \\
\hline Has had infections while hospitalized & 50 & 7.9 & 581 & 92.1 \\
\hline Has had allergic reactions & 33 & 5.2 & 598 & 94.8 \\
\hline Has had another surgery unexpectedly & 32 & 5.1 & 599 & 94.9 \\
\hline Had fallen, had a fracture, or a wound & 7 & 1.1 & 624 & 98.9 \\
\hline Health staff was wrong in their diagnosis & 10 & 1.6 & 621 & 98.4 \\
\hline Got a wrong medication during hospitalization & 11 & 1.7 & 620 & 98.3 \\
\hline Was confused with another patient & 23 & 3.6 & 608 & 96.4 \\
\hline
\end{tabular}

Note. Source: PSHC; $n=631$

Only 30 patients answered when asked about the experience with the clinical error, about the error being detected quickly, 20 (3.2\%) agreed; when asked if it was satisfactorily resolved, 26 (4.3\%) mentioned agreeing; if the error was solved quickly, $21(3.3 \%)$ patients agreed; referring to the information received from the staff about the error, 22 (3.5\%) 
agreed. When asked if they had participated in the decisionmaking to resolve the error, 20 (3.2\%) patients agreed; about the health staff apologizing for the error occurred, $9(1.5 \%)$ agreed and $21(3.3 \%)$ of the patients expressed disagree- ment; when asked if the health personnel informed them if they would take steps to prevent the error from recurring, 9 $(1.4 \%)$ patients mentioned agreeing and $21(3.3 \%)$ of patients disagreed (see Table 4).

Table 4. Response of patients to the experience clinical errors

\begin{tabular}{|c|c|c|c|c|c|c|c|c|c|c|}
\hline \multirow[t]{2}{*}{ Questions } & \multicolumn{2}{|c|}{$\begin{array}{c}\text { Strongly } \\
\text { disagree } 1\end{array}$} & \multicolumn{2}{|c|}{ Disagree 2} & \multicolumn{2}{|c|}{$\begin{array}{c}\text { Undecided } \\
3\end{array}$} & \multicolumn{2}{|c|}{ Agree 4} & \multicolumn{2}{|c|}{$\begin{array}{c}\text { Strongly } \\
\text { agree } 5\end{array}$} \\
\hline & $\mathbf{f}$ & $\%$ & f & $\%$ & $\mathbf{f}$ & $\%$ & $\mathbf{f}$ & $\%$ & $\mathbf{f}$ & $\%$ \\
\hline Clinical error was quickly detected & 5 & 0.8 & 3 & 0.5 & 2 & 0.3 & 8 & 1.3 & 12 & 1.9 \\
\hline Clinical error was solved satisfactorily & 1 & 0.2 & 3 & 0.5 & - & - & 10 & 1.6 & 16 & 2.5 \\
\hline Clinical error was solved quickly & 1 & 0.6 & 2 & 0.3 & 3 & 0.5 & 9 & 1.4 & 12 & 1.9 \\
\hline $\begin{array}{l}\text { Information received from medical staff about the clinical } \\
\text { error suffered was sufficient and clear }\end{array}$ & 6 & 1.0 & 2 & 0.3 & - & - & 8 & 1.3 & 14 & 2.2 \\
\hline $\begin{array}{l}\text { Was able to participate in decision making regarding the way } \\
\text { to solve the clinical error or problem }\end{array}$ & 8 & 1.3 & 2 & 0.3 & - & - & 7 & 1.1 & 13 & 2.1 \\
\hline Health staff apologized for clinical error & 14 & 2.2 & 4 & 0.6 & 3 & 0.5 & 3 & 0.5 & 6 & 1.0 \\
\hline $\begin{array}{l}\text { Health staff informed that steps would be taken prevent error } \\
\text { from recurring }\end{array}$ & 17 & 2.7 & 2 & 0.3 & 2 & 0.3 & 2 & 0.3 & 7 & 1.1 \\
\hline
\end{tabular}

Regarding the results obtained for the general question about the feeling of safety during their hospital stay, $41.97 \%$ of the patients felt very safe, $32.91 \%$ reported feeling quite safe, $15.26 \%$ mentioned feeling slightly safe, so it is considered that the sense of safety of the patients in the four hospitals was quite good.

And the results about overall patients' perception of safety in four hospitals included in the study, the ISSSTE hospital in Tampico obtained the highest perceived safety (90\%), followed by the Civil Hospital in Cd. Madero (85\%), the HGCC in Tampico with $80 \%$ perceived safety and the last the IMSS in Cd. Madero.

\section{Discussion}

In 2004, the Health Secretary in Mexico established different strategies to reduce the rising costs of health care that were derived from the clinical errors that arose during the provision of patients' health care. Despite these efforts to establish preventive actions to reduce the clinical errors and their complications, these goals have not been achieved. This study describes the perceived safety of 631 patients hospitalized from August to November of 2013 in four hospitals in Tampico and Cd. Madero, Tamaulipas, Mexico. The perceived safety was considered to be very good and has similarities with the results reported in other studies. ${ }^{[14-18]}$ The authors reported that patients had very positive perception of clinical safety during hospitalization. About $75 \%$ of the patients are women with a mean age of 51 years. A total of $16.5 \%$ presented complications. Our results differ from those by other studies, ${ }^{[2,6]}$ which reported that $13 \%$ and $47 \%$ of 18 their patients respectively experienced clinical error. When compared to the average of days of hospitalization, another author ${ }^{[14]}$ reported an average of 15.4 days and in this study the mean was 9.80 .

Related to complications, results differ to that reported by another author, ${ }^{[16]}$ since $5.5 \%$ of patients on dialysis and $10 \%$ of patients on hemodialysis reported having a complication, and in this study only $16.5 \%$ of the participants reported complications.

The questionnaire aimed to explore the perception of patients about the nursing care they receive, such feedback should help managers when developing possible strategies for improvement in health care. It always has to be present that patient safety - along with satisfaction and efficient use of resources, is one of the aspects closely linked to quality of care.

\section{Conclusion}

The findings in this study have several implications for quality improvement in the studied hospitals. Also, continuous assessment of patient safety culture in the studied hospitals could encourage the staff to report AEs without being punished. Such assessments are the foundation for quality improvement.

These results will encourage research into a more explicit understanding of the issues and identification of strategies to address patient safety in health care. Nurses are critical to the surveillance and coordination that reduce adverse outcomes. Much work remains to be done in Mexico in evaluating the impact of nursing care on positive quality indicators. 


\subsection{Limitations of the study}

The questionnaire is self-filled in, thus the possibility of professionals handling it to the patients without all the necessary previous explanations, leading to bias in the results.

\subsection{Strengths of the study}

It has been highlighted the importance of patients' involvement in clinical safety during hospitalization.

\section{ACKNOWLEDGements}

This work is supported by PROMEP, México, under the Grant No.: FDEPSAL-0849AP18.

\section{CONFLicts of InTEREST Disclosure}

The authors declare they have no conflicts of interest.

\section{REFERENCES}

[1] Davis RE, Sevdalis N, Vincent CA. Patient involvement in patient safety: How willing are patients to participate? Revista BMJ Quality Safety [Internet]. 2011; 20 (1): 108-114. PMid: 21228083. https://doi.org/10.1136/bmjqs. 2010.041871

[2] Hernández ME, Ochando GA, Rayuela GC, et al. Seguridad clínica percibida por los pacientes en diálisis peritoneal (Clinical safety perceived by patients on peritoneal dialysis). Revista Social Especialidad. Enfermera Nefrología. 2008; 11(3): 190-195.

[3] Mira JJ, Vitaller J, Lorenzo S, et al. Pacientes como informadores de eventos adversos. Resultados en diabetes y enfermedad renal (Patients informing of adverse events. Results in diabetes and kidney disease). Revista Anales Sistema Sanitario Navarro [Internet]. 2012; 35(1): 1928. https://doi.org/10.4321/S1137-66272012000100003

[4] Mira JJ, Lorenzo S, Vitaller J, et al. El punto de vista de los pacientes sobre la seguridad clínica de los hospitales. Validación del cuestionario de percepción de seguridad (Hospital clinical safety from the patient's point of view. Validation of a safety perception questionnaire). Revista Médica de Chile. 2009; 137(11): 1441-1448. https://doi.org/10.4067/S0034-98872009001100005

[5] Prieto RM, March CJ, Suess A, et al. Percepción de los pacientes sobre la seguridad de la asistencia sanitaria (Patient perceptions on healthcare safety). Revista Medicina Clínica. 2008; 131(3): 33-38.

[6] Mira JJ, Aranaz JM, Vitaller J, et al. Percepción de seguridad clínica tras el alta hospitalaria (Perceptions of clinical safety after hospital discharge). Revista Medicina Clínica. 2008; 131(3): 26-32. https ://doi.org/10.1016/S0025-7753(08)76458-3

[7] Vázquez CE, Esperato A, Klavano D. Red de pacientes por la seguridad del paciente: un rayo de esperanza (Patients for Patient Safety: A ray of hope). Revista Digital Universitaria. 2012; 13(8): 1-11. Available from: http://www.revista.unam.mx/vol.13/num8/ art82/index.html

[8] Vázquez CE. Seguridad del paciente. Una necesidad para el cuidado (Patient safety. A need for care). Revista Enfermería Universitaria. 2008; 5(1): 30-34. Available from: http: //www.revistas . unam . $\mathrm{mx} /$ index.php/reu/article/view/30261/38453

[9] Greenberg GL, Battles BJ, Haskell H. Aprendiendo del paciente para mejorar los sistemas de informes de eventos de seguridad (Learnijnf from patients to improve reporting systems of safety events). Revista Cirugía y Cirujano. 2010; 78(5): 463-468.
[10] Zarza-Arizmendi M, Alba-Leonel A, Salcedo-Álvarez RA. El currículum de la enfermera y la seguridad del paciente (The nursing curriculum and the patient safety). Revista CONAMED. 2008; 13(3): 33-37.

[11] Burns N, Grove S. The Practice of Nursing Research, $8^{\text {th }}$ Ed. Spain: Elsevier Madrid; 2012. 260-95 p. PMid: 22918902.

[12] Badia LX, Terol GE, Agra VY, et al. Evaluación de la percepción de los pacientes sobre la seguridad de los servicios sanitarios. Dise-o y validación preliminar (Assessment of patient perception of sanitary services safety. Preliminar tool validation). Madrid, Espa-a: Ministerio De Sanidad, Política Social E Igualdad; 2010

[13] Secretaría de Salud. Reglamento de la ley general de salud en materia de investigación para la salud (Regulations of the Genearl Law for health research). México: Diario Oficial de la Federación; 1984 98-113 p.

[14] Guzmán CR, Caba-as CM, Calvo DM, et al. Estamos en Buenas Manos (Are we in good hands)? XI Congreso Nacional Asociación Espa-ola de Enfermería en Traumatología y Ortopedia AEETO. Madrid, Espa-a. Hospital 12 de Octubre; 2012. Available from: http://www. codem.es/carteles-o-posters/estamos -en-buenas-manos

[15] Weingart SN, Zhu J, Chiappetta L, et al. Hospitalized patients' participation and its impact on quality of care and patient safety. International Journal for Quality in Health Care. 2011; 23(3): 269-277. https://doi.org/10.1093/intqhc/mzr002

[16] Santos S, Álamo MJ, Maribel GM, et al. Percepción de seguridad clínica de pacientes en una unidad de terapia endovascular (Perception of Patients' Clinical Safety In A Unit Of Endovascular Therapy). Revista Enfermería en Cardiología. 2010-2011; 51-52(3): 52-57.

[17] Agencia de Calidad Asistencial del Sistema Nacional de Salud (ACASNS). Análisis de la cultura sobre seguridad del paciente en el ámbito hospitalario del Sistema Nacional de Salud Espaol (Agency for care quality of Spanish Health National System. Analysis of patient safety culture in hospitals). Madrid, Espa-a: Ministerio De Sanidad, Política Social E Igualdad. 2009. Available from: http://www.msc.es/organizacion/sns/planCa lidadSNS/docs/Analisis_cultura_SP

[18] Mazor MK, Roblin WD, Greene MS, et al. Toward patient-centered cancer care: patient perceptions of problematic events, impact, and response. Journal of Clinical Oncology. 2012; 30(15): 1784-1790. https://doi.org/10.1200/JC0.2011.38.1384 